\title{
DINÁMICA ESPACIO-TEMPORAL DEL USO DEL SUELO Y SU EFECTO SOBRE LA DEGRADACIÓN DE LOS RECURSOS HÍDRICOS: CASO DE LA CUENCA DEL RÍO JUQUERI - BRASIL
}

\author{
SPACE-TEMPORAL DYNAMICS OF THE USE OF LAND AND ITS \\ EFFECT ON THE DEGRADATION OF WATER RESOURCES: \\ CASE OF THE JUQUERI RIVER BASIN - BRAZIL
}

\author{
Diego Javier Perez Ortega ${ }^{1}$ \\ Jesus Geovanny Solarte ${ }^{2}$ \\ Jonny Jair Pantoja Díaz ${ }^{3}$ \\ Marcelo Luiz Martins Pompêo ${ }^{4}$ \\ ${ }^{1}$ Doctor en Ciencias Ambientales. Universidad de Nariño. Colombia. \\ 2 Magister en Ingeniería Ambiental. Universidad de Nariño. Colombia. \\ ${ }^{3}$ Estudiante de Maestría. Universidad de Nariño. Colombia. \\ ${ }^{4}$ Doctor en Ciencias de la Ingeniería Ambiental. \\ 1 diegojperez77@gmail.com \\ 2 solarteg@hotmail.com \\ 3 jonny912@javerianacali.edu.co \\ 4 mpompeolib.usp.br
}

\section{Resumen}

Los cambios en los usos del suelo influyen el paisaje de una cuenca. Las trasformaciones provocadas por las actividades antrópicas, generan impactos en sus recursos naturales. Estos pueden ser identificados para generar mitigaciones futuras mediante el monitoreo de la cobertura del suelo. Este trabajo presenta un análisis espacio-temporal de la dinámica del uso del suelo de la cuenca del río Juqueri, partiendo de la clasificación de imágenes satelitales de sensores LANDSAT 5, 7 y 8 de los años
1986, 1992, 2003, 2011 y 2016, usando metodologías de máxima verosimilitud, álgebra de mapas y procesamiento digital, mediante el software ArcGIS 10.3. Los resultados mostraron una transición ambiental negativa, con la sustitución progresiva de las áreas de vegetación por pastos, agricultura y suelos expuestos, además de un rápido crecimiento de áreas urbanas. La clase predominante es el bosque nativo debido a la existencia de la Ley de Protección de Manantiales de Brasil (Ley Estatal 
9.866/97) que ha ayudado en la conservación de esta clase. Infortunadamente, al transcurrir del tiempo, los bosques fueron fragmentados y disminuidos un 15,88 \% y el área urbana aumentó en $13,49 \%$, disminuyendo también el área de los recursos hídricos en $0,42 \%$ cuando se compararon los valores de los años de 1986 y 2016. Según el Índice de Transformación Antrópica (ITA), la cuenca se clasificó como $R e$ gularmente Degradada, mostrando una fuerte presión y degradación ambiental sobre sus recursos hídricos.

Palabras clave: actividades antrópicas, degradación ambiental, geoprocesamiento, paisaje.

\section{Abstract}

The changes in land-use influence the landscape of a basin. The transformations caused by the anthropic activities generate impacts on their natural resources. These can be identified to generate future mitigations by monitoring ground cover. This paper presents a spatio-temporal analysis of the dynamics in the land-use of the Juqueri River basin, based on the classification of satellite images of LANDSAT sensors 5, 7 and 8 of the years 1986, 1992, 2003, 2011 and 2016, using methodologies of maximum likelihood, map algebra and digital processing with ArcGIS 10.3 software. The results showed a negative environmental transition with the progressive substitution of vegetation in grassland, agriculture and exposed soils areas, in addition to a rapid growth of urban regions. The predominant class is native forest due to the existence of the Brazilian Water Protection Act (State Law 9.866 / 97) that has helped in the conservation of this type. Unfortunately, over time, forests were fragmented and decreased by $15.88 \%$ and the urban area increased by $13.49 \%$, while the water resources area decreased by $0.42 \%$ when compared to the values of the years of 1986 and 2016. According to the Anthropic Transformation Index (ATI), the basin was classified as Regularly Degraded, showing strong pressure and environmental degradation on its water resources.

Keywords: anthropic activities, environmental degradation, geoprocessing, landscape.

\section{Introducción}

La ocupación desordenada del suelo, el crecimiento demográfico, la escasez de recursos hídricos y la pérdida de suelos fértiles determinan la necesidad de generar estrategias y directrices que proporcionen aptitudes (destrezas) de los ecosistemas con los usos y ocupaciones de los suelos para ser capaces de mantener la biodiversidad y su sostenibilidad a largo plazo (Leite \& Matsumoto, 2007). La cuenca del río Juqueri se caracteriza por tener un valle definido encajado en su área, vegetación ciliar, una creciente ampliación del área de ocupación urbana, junto a los principales tributarios, donde predomina un grado de conservación de vegetación secundaria, bosque nativo y un uso de suelo de agricultura de subsistencia en diferentes escalas. Además, dentro de la Cuenca del río Juqueri, se encuentra un manantial extremadamente importante para la Gran São Paulo, el embalse Paiva Castro, que también constituye una opción de descanso y turismo para los diversos habitantes de las ciudades de Mairiporã, Guarulhos, Caieiras y la zona norte del municipio de São Paulo (Giatti, 2000).

Las imágenes de satélite son de gran ayuda, ya que reunieron datos históricos para una reconstrucción ambiental del pasado 
ayudando en el diagnóstico de las repercusiones que las actividades antrópicas que se ejercen en la cuenca y en específico en los recursos hídricos. Por otro lado, los Sistemas de Información Geográfica (SIG), ayudan en el análisis de esta dinámica del espacio geográfico y de su configuración, además del sensor remoto para la obtención de imágenes mediante plataformas remotas orbitales (satélites) que proporciona una cantidad de informaciones sobre la cuenca en estudio (Haddad, 2007).

Los análisis espacio-temporales sirven fundamentalmente para comprender los cambios en el uso del suelo y los fenómenos ambientales, así como las velocidades de los procesos de degradación ambiental causados en los ecosistemas por las actividades antrópicas (Santos, 2009).

El objetivo de esta investigación fue determinar la dinámica espacio-temporal del uso del suelo y su efecto sobre la degradación de los recursos hídricos de la Cuenca del río Juqueri, realizando un diagnóstico ambiental de los impactos causados por la ocupación no planificada del espacio. Esto atribuyendo un grado de degradación sobre el paisaje modificado utilizando el Índice de Transformación Antrópica (ITA).

\section{Materiales y métodos}

En la Figura 1 se presenta la secuencia metodología utilizada.

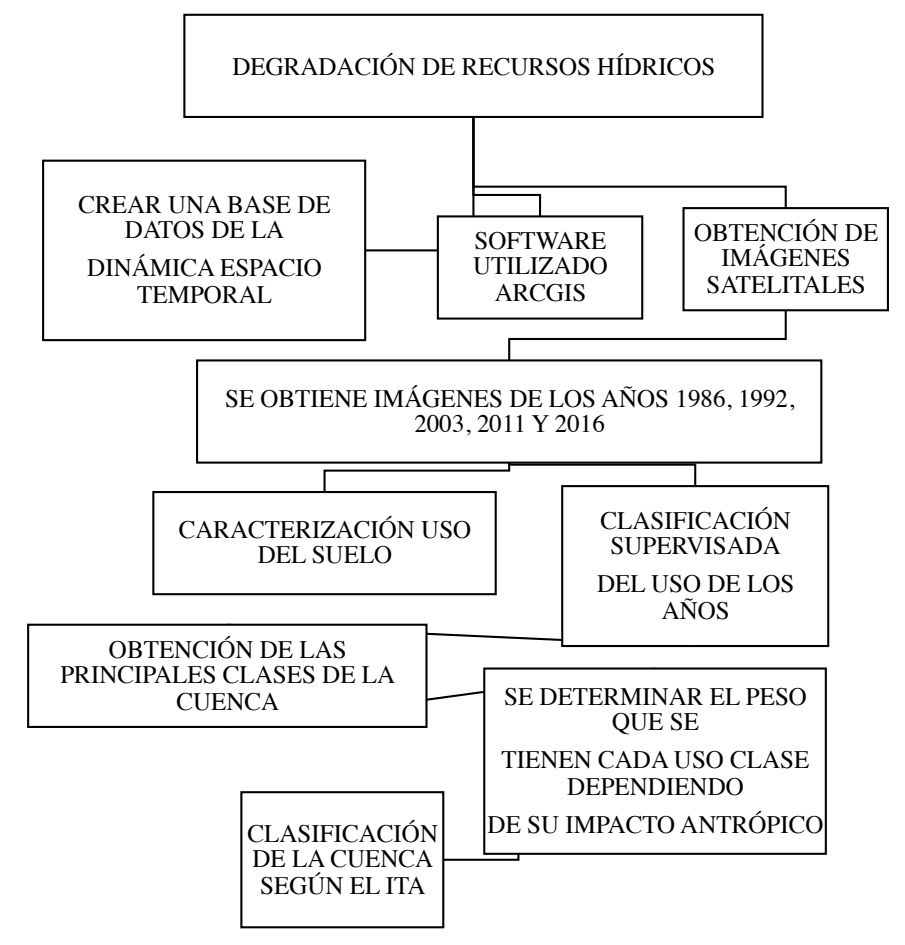

Figura 1. Diagrama de flujo del proceso metodológico implementado

\section{Localización de la Cuenca del Juqueri en el municipio de Mairiporã-SP}

La localización geográfica de la cuenca del río Juqueri se encuentra en la latitud S 23⒉ ${ }^{\prime} 25^{\prime \prime}$ y longitud W 4552'40", con la mayoría de su área en el municipio de Mairiporã. Además, posee partes de los municipios como: Atibaia, Nazaré Paulista, Guarulhos, Caieiras y Franco da Rocha (Emplasa, 2000). El área de la Cuenca del río Juqueri cuenta con $307,0 \mathrm{~km}^{2}$ de los 
cuales $114 \mathrm{Km}^{2}$ representan el área urbana, siendo que el $80,1 \%$ del total se sitúa dentro del área de la Ley de Protección a los Manantiales (Emplasa, 2000) (Figura 2).

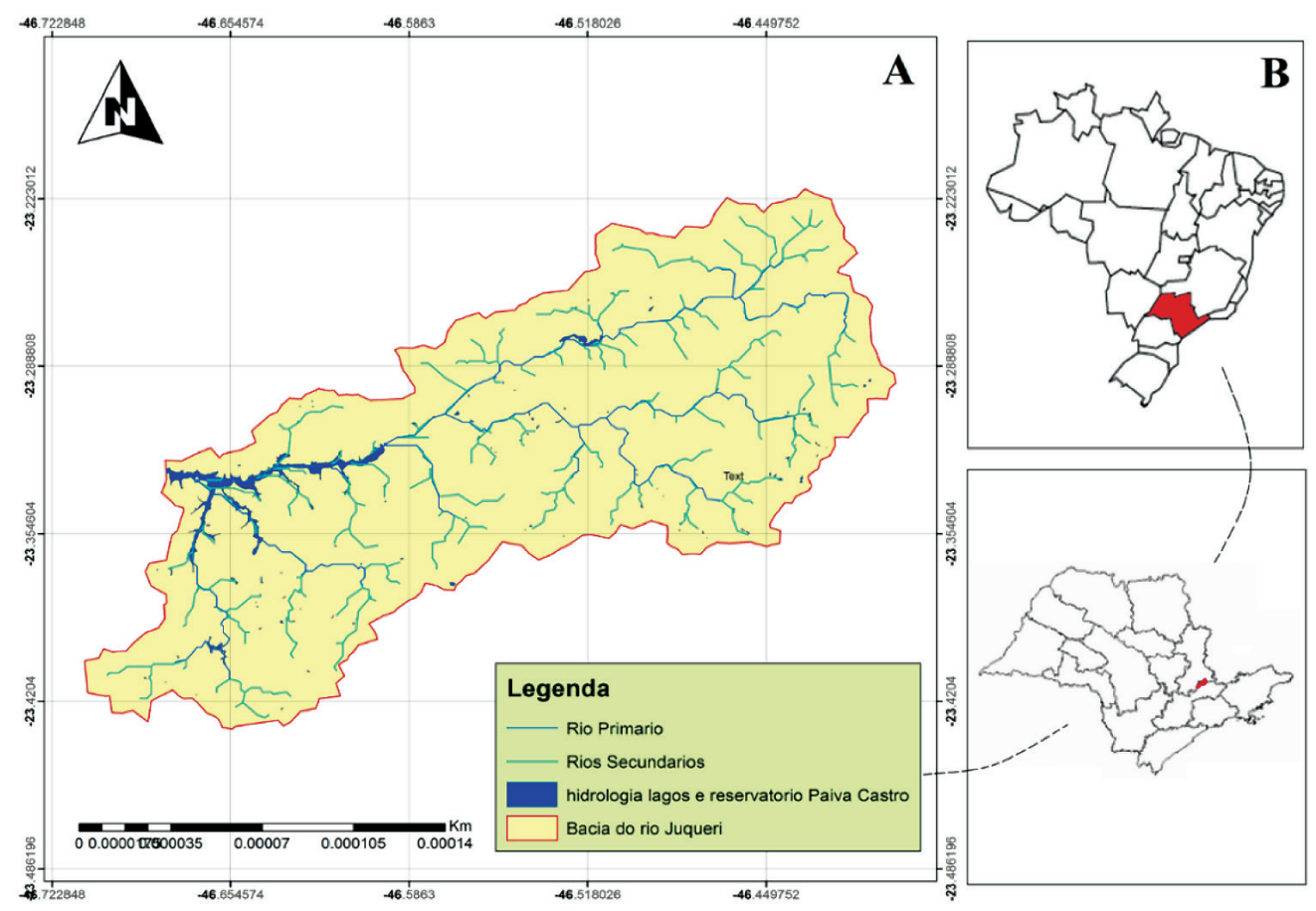

Figura 2. Localización de la Cuenca del río Juqueri (A) en Brasil y en el Estado de São Paulo (B). Fuente: Elaboración propia.

\section{Caracterización del uso y ocupación del suelo de la Cuenca del río Juqueri}

Este análisis fue realizado utilizando unidades funcionales del paisaje del área de la cuenca, de los diferentes tipos de usos del suelo, utilizando sensores remotos, geoprocesamiento y modelación ambiental. Este método fue utilizado para el modelado espectro espacio-temporal, para la identificación del uso del suelo y los análisis de las unidades funcionales del paisaje y del área de la cuenca.

Para la elaboración de los mapas de uso del suelo de los años 1986, 1992, 2003, 2011 y 2016, se realizaron combinaciones de 3 a 8 bandas multiespectrales obtenidas de los satélites Landsat 5, 7 y 8 con sus respectivas firmas espectrales de las clases de cobertura obtenidas en la web del Geological Survey of the United States - USGS y donde para la clasificación del área estudiada, se utilizó un método supervisado de interpretación en el Programa ArcGIS. (Tabla 1).

En cuanto a las imágenes insertadas en la base de datos, se aplicaron los procedimientos de preprocesamiento, es decir, realce de imágenes, haciendo la corrección atmosférica de esas por medio de la herramienta (Radiance with atmospheric corretion) de ArcGIS 10.3. Al terminar la restitución de las imágenes, el paso siguiente fue obtener los valores de reflectancia para las seis clases de uso del suelo: 1) bosques; 2) cuerpos de agua; 3) pastos; 4) suelo expuesto; 5) áreas urbanas y 6) áreas agrícolas. 
Tabla 1. Imágenes utilizadas para caracterizar el uso del suelo Cuenca del río Juqueri

\begin{tabular}{l|c|c|c|c|c|c|}
\hline Año & Satélite /Sensor & Imagen de satélite/ Entity ID & Datum & UTM Zone & Panth \\
\hline 1986 & L1-5/MSS & LT52190761986298CUB00 & WGS84 & 23 & 219 \\
\hline 1992 & L1-5/MSS & LT52190761992206CUB00 & WGS84 & 23 \\
\hline 2003 & LL-7/ETM & MES-23-20_LL_2003 & WGS84 & 23 & 219 \\
\hline 2011 & L1-5/TM & LT52190762011207CUB00 & WGS84 & 23 \\
\hline 2016 & L1-8/OLI_TIRS & LC82190762016206LGIN00 & WGS84 & 23 \\
\hline Año & Row & Fecha de Adquisición & Fecha de & File Format & Bandas \\
\hline 1986 & 76 & $25 / 10 / 1986$ & $12 / 12 / 2014$ & Geo TIFF & $1-4$ \\
\hline 1992 & 76 & $21 / 07 / 1992$ & $12 / 12 / 2014$ & Geo TIFF & $1-4$ \\
\hline 2003 & 76 & $23 / 09 / 2003$ & $12 / 12 / 2014$ & Geo TIFF & $1-7$ \\
\hline 2011 & 76 & $26 / 07 / 2011$ & $12 / 12 / 2014$ & Geo TIFF & $1-7$ \\
\hline 2016 & 76 & $05 / 07 / 2016$ & $11 / 11 / 2016$ & Geo TIFF & $1-8$ \\
\hline
\end{tabular}

Existen errores al comparar las imágenes de diferentes sensores, debido al tipo de resoluciones. Otra diferencia notable es la reflectancia en las bandas correspondientes que cada sensor produce, ya que la clasificación visual (supervisada) cumple un papel muy importante a la hora de la clasificación del uso del suelo para cada imagen, pues por medio de técnicas de interpretación visual se generaron los resultados buscando la mayor veracidad en la clasificación final. Se presentan ciertas inconsistencias en las imágenes de los sensores Landsat de los años 1986 y 1992, pues éstas poseían un bajo contraste espectral de las áreas agrícolas con los suelos expuestos, dificultando su correcta clasificación por su semejanza. De esta forma, fue necesario realizar la delimitación de polígonos de las áreas agrícolas manualmente.

\section{Clasificación supervisada del uso del sue- lo de la cuenca del río Juqueri}

Para determinar la dinámica espacio-temporal de la cuenca, se utilizaron imágenes de los sensores Landsat 5, 7 y 8, donde fue necesario utilizar el sensor remoto para generar los mapas de uso y cobertura del suelo de la cuenca de los períodos de los años 1986, 1992, 2003, 2011 y 2016. Estas imágenes mostraron las modificaciones de las clases de uso del suelo en relación al área ocupada. Ya que para esos análisis se realizó un cruce entre los mapas de uso y cobertura del suelo para así identificar los cambios de las clases obtenidas en los períodos establecidos.

\section{Uso de suelos de 1986, 1992, 2003, 2011 y 2016.}

Los años no fueron elegidos al azar ni en función de un criterio técnico específico. Estos fueron seleccionados en virtud del material disponible que presentó la mejor calidad y las mejores imágenes del satélite Landsat 5, 7 y 8. A partir de las imágenes obtenidas fue posible identificar los posibles cambios en la cobertura del suelo para la Cuenca del río Juqueri. Las imágenes obtenidas por el satélite son de fácil acceso, ya que están disponibles gratuitamente en el sitio USGS.

Por lo tanto, se sabe que al comparar imágenes del satélite Landsat 5, 7 y 8, tendremos 
algunos inconvenientes que producen ciertas limitaciones como: órbita que se encuentra el satélite/ punto adquirido, fecha de la imagen, bandas espectrales, elevación solar, azimut solar y su resolución. Sin embargo, lo que se buscó fue utilizar una herramienta gratuita que ayudara a entender la dinámica en los cambios del uso del suelo de la Cuenca en determinados períodos de tiempo e identificar la degradación en los recursos hídricos por esos cambios.

Los análisis para esta investigación se realizaron utilizando unidades funcionales del paisaje del software ArcGIS 10.3. Se realizó una clasificación inicial no supervisada para ver cuántas clases el software podía distinguir con facilidad y calidad. Se realizaron ensayos con 10 y 7 clases, pero sin resultados satisfactorios y con problemas para la clasificación, donde los mejores resultados fueron obtenidos al clasificar 6 clases. El método utilizado fue (Iso Cluster) que utiliza un algoritmo de agrupamiento de isodatos para determinar las características de las agrupaciones naturales de células en el espacio.

Los atributos multidimensionales almacenaron los resultados en un archivo de firma ASCII de salida para posteriormente realizar la clasificación por el método (Maximum Likelihood Classification) que realiza una clasificación de máxima verosimilitud con las 6 clases: 1) cuerpos de agua; 2) bosque; 3) pasto; 4) áreas urbanas; 5) suelo expuesto y 6) áreas agrícolas, en un conjunto de bandas Raster y crea un Raster clasificado como producto final (Figura 3).

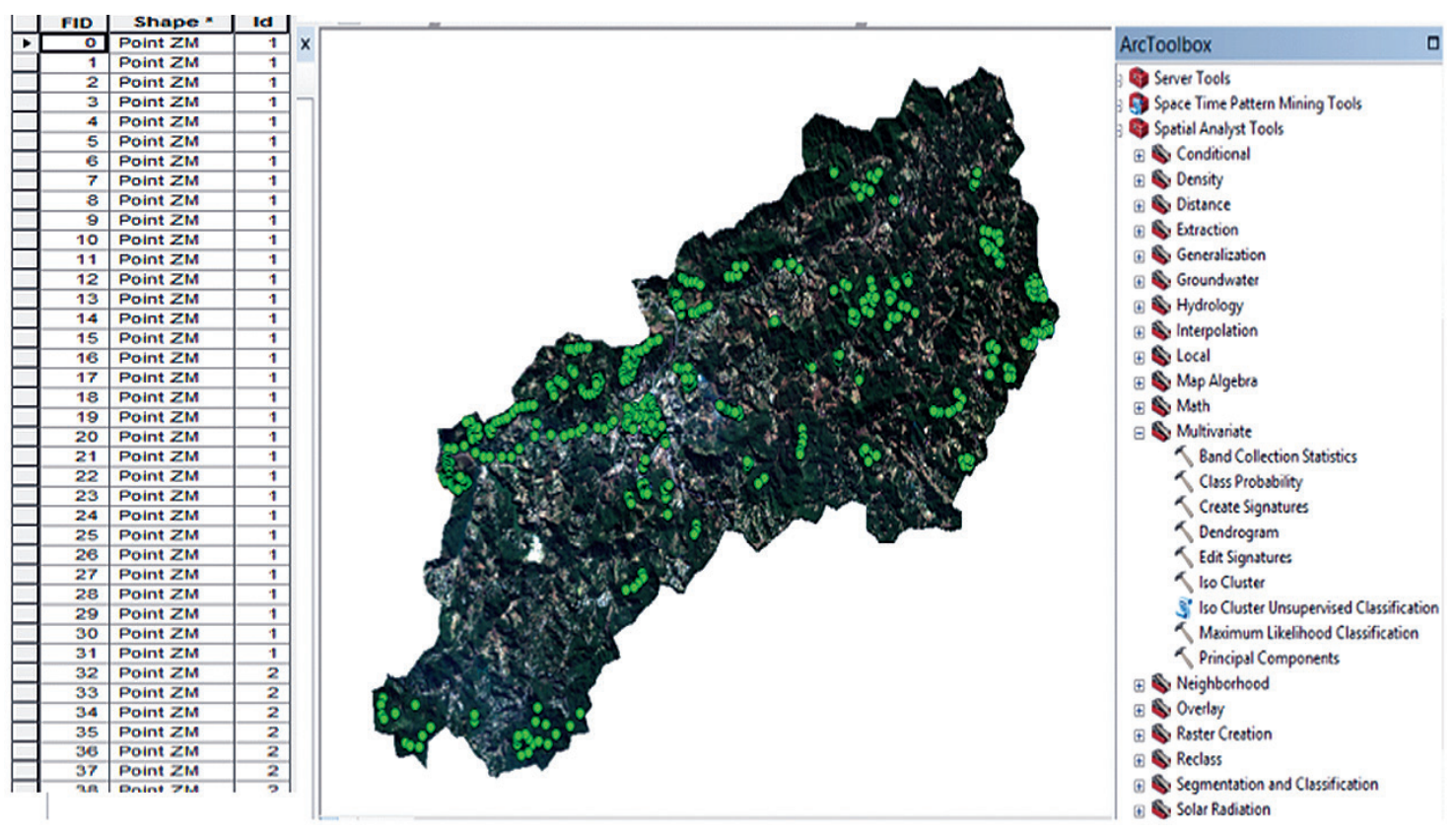

Figura 3. Método de clasificación de máxima verosimilitud.

Fuente: Elaboración propia.

Índice de transformación antrópica - ITA Este índice precisa de técnicas de geoprocesamiento y la utilización de imágenes de satélites para su aplicación satisfactoria. Los resultados de las variables obtenidas de los análisis de los cambios en el uso del suelo forman parte del Índice de Transformación Antrópica (ITA), el cual realizó un análisis espacio-temporal 
sistemático, comparativo y cualitativo; que estableció los efectos de las actividades antrópicas sobre los diferentes elementos de los ecosistemas de la cuenca. Algunos de los cuidados que deben tenerse en cuenta son: la compatibilidad de los datos tomados en el área de estudio, el detalle establecido en los mapas y el objetivo del trabajo.

El ITA tiene el objetivo de cuantificar la presión antrópica sobre las cuencas hidrográficas. Al aplicar el ITA se identificaron impactos causados por el uso de suelos y la ocupación no planificada de los suelos, determinándose un grado de deterioro en su paisaje y ayudando en la identificación de áreas sensibles a la degradación ambiental.

Para calcula el ITA se depende de diversas variables condicionantes, dentro de ellas, se puede citar: la vegetación, uso actual de suelos, relieve, entre otras. Estos son factores que, dependiendo de su situación actual, influenciaron en la transformación del paisaje de la cuenca. Para aplicar el ITA se realizó un análisis multicriterio que permitió generar información mediante la aplicación de operaciones aritméticas para asociar los diferentes valores dados a la actividad encontrada em el uso actual del suelo de la cuenca de estudio. Existen dos pasos para aplicar el ITA: a) Identificar los diferentes usos de suelo de la cuenca de estudio. b) Determinar el peso que se tienen cada uso del suelo dependiendo de su impacto antrópico, este valor es dado por diferentes especialistas, a continuación, se muestra los valores dados a este estudio:

- Cuerpos de agua (CA): el peso dado fue de 3 , debido a problemas de inundaciones y la permanencia de áreas inundadas que pueden propiciar la proliferación de mosquitos y enfermedades; se aclara que este peso no quita la importancia de tener grandes áreas de recursos hídricos.

- Bosque (F): el peso dado fue de 2, debido a posibles quemas que pueden ocurrir accidentalmente emitiendo carbono, erosión de suelos con metales, y aportes de materia orgánica;

- Pastos (P): el peso dado fue de 7, debido a la expansión de áreas para ganado, lo que posibilita la deforestación. Estas áreas, progresivamente, pasan a ser áreas de suelo expuesto además de presentar otros problemas, como sobrepastoreo, compactación y erosión creada por la acción del ganado y producción de metano;

- Áreas Urbanas (AU): el peso dado fue de 9, debido a la expansión urbana desordenada, instalación de industrias, avenidas asfaltadas e impermeabilización de suelos;

- Solo Expuesto (SE): el peso fue de 8, debido a la pérdida de suelo y capa fértil de este, además de la pérdida de nutrientes y materia orgánica, contaminación de recursos hídricos por sedimentación, erosión, disponibilidad de $\mathrm{N}, \mathrm{P}$, metales y otros elementos;

- Área agrícola (AA): peso 7, debido a la pérdida de suelo, pérdida de nutrientes y materia orgánica, contaminación de recursos hídricos por erosión y sedimentación, disponibilidad de nutrientes, pesticidas y agrotóxicos.

\section{Clasificación de las cuencas en cuanto al índice de transformación antrópica}

Para calcular el índice en la Cuenca del río Juqueri, se clasificaron las áreas como un todo, dando como resultados los valores y su evaluación (Mateo, 1984): I) Poco degradado (0 a 2,5); II) Regularmente Degradado (2,5 a 5); III) Degradado (5 a 7,5); IV) Muy Degradado (7,5 a 10). Finalmente, el resultado del ITA se divide por 100, según la propuesta 
metodología de Lémechev (1982) que cuantifica el grado antrópico.

\section{Resultados y discusión Uso del suelo en el año 1986}

Según las imágenes de satélite estudiadas en esta investigación, la Cuenca del río Juqueri aún presenta un buen porcentaje de bosque, con el $67,25 \%$ del total del área de la cuenca. Hay que considerar, sin embargo, que el área de bosques fue sustituida por cultivos de eucaliptos para la obtención de leña, utilizada para suplir las necesidades de las alfarerías que producían una cantidad significativa de ladrillos para la gran metrópolis de São Paulo. Se cree que, por este motivo, la imagen satélite del Landsat 5 referente al año 1986, mostró buena cantidad de bosque, ya que la silvicultura, con la introducción del eucalipto (por su fácil y rápido crecimiento) ocupó las áreas de pastoreo y antiguas áreas de producción agrícola de baja productividad. Según Mantovani (2003), en la cuenca existían áreas y loteo con pastos para la cría de ganado en pequeña escala y pequeños rastros de vegetación de Mata Atlántica

Se determino también una buena parte del área (904 ha) de la cuenca con problemas de suelo expuestos. Estos son muy susceptibles a cualquier tipo de erosión, y puede haber sido consecuencia de las necesidades de suelo para la producción de ladrillos de las alfarerías que eran muy comunes en esa época (Tabla 2 ).

Tabla 2. Valores en hectáreas del uso del suelo de la Cuenca del rio Juqueri

\begin{tabular}{l|c|c|c|c|c|c}
\hline Clases & $\mathbf{1 9 8 6}$ & $\mathbf{1 9 9 2}$ & $\mathbf{2 0 0 3}$ & $\mathbf{2 0 1 1}$ & $\mathbf{2 0 1 6}$ & Total, área 1986 - 2016 \\
\hline Cuerpos de agua & 371 & 364 & 341 & 324 & 229 & -142 \\
\hline Bosques & 22673 & 21526 & 20876 & 20481 & 17319 & -5354 \\
\hline Pastos & 8243 & 3129 & 2657 & 5293 & 5131 & +3112 \\
\hline Áreas Urbanas & 1355 & 2424 & 3368 & 4396 & 5903 & +4548 \\
\hline Suelo expuesto & 904 & 6001 & 6136 & 2377 & 3796 & +2893 \\
\hline Áreas agrícolas & 169 & 270 & 337 & 843 & 1335 & +1167 \\
\hline Total & 33714 & 33714 & 33314 & 33714 & 33714 & \\
\hline
\end{tabular}

Los valores en rojo son las áreas de uso del suelo que han sido áreas que están siendo disminuidas.

\section{Uso y ocupación de suelos para el año 1992}

En este período la valorización de tierras para lotes y ventas se incrementó (Fadini, 2005). Según Hoeffel et al., (2004) la existencia de actividades, como la reforestación (con eucalipto) para la producción de carbón, además de la construcción de la Avenida Fernão Días y del embalse Paiva Castro, hizo que São Paulo viera al municipio de Mairiporã como un gran potencial para el sector inmobiliario, debido a su cercanía a la ciudad y a su gran belleza escénica (Figura 4). Ver Anexo

Esto tuvo como consecuencia un aumento en el valor de los terrenos, así como en la multiplicación de parcelas para la venta, lo que generó un aumento poblacional en el área urbana de la región, que del 4,02\% del área total de la cuenca en el año 1986, se duplicó en 6 años, pasando a 7,19\% del área total para el 
año 1992. Obviamente, eso fue el comienzo de la disminución creciente de las clases como bosque, la cual se redujo su área en un 3,4\%; de la clase cuerpos de agua, también se determinó una reducción de un 0,02\%; y las áreas con suelo expuesto, aumentaron un $15,12 \%$ en los mismos años. Se cree que los terrenos pasaron a ser destinados a la construcción de casas y demás edificaciones urbanas (Tabla 3 ).

Tabla 3. Dinámica en \% de las clases resultantes del uso de suelo.

\begin{tabular}{|c|c|c|c|c|c|c|c|c|c|c|c|}
\hline Clases & 1986 & $\begin{array}{c}1992 \text { - } \\
1986\end{array}$ & 1992 & $\begin{array}{c}2003- \\
1992\end{array}$ & 2003 & $\begin{array}{c}2011 \text { - } \\
2003\end{array}$ & 2011 & $\begin{array}{c}2016- \\
2011\end{array}$ & 2016 & TOTAL & ÁREA \\
\hline $\begin{array}{l}\text { Cuerpos } \\
\text { de agua }\end{array}$ & 1,1 & $-0,02$ & 1,08 & $-0,07$ & 1,01 & $-0,05$ & 0,96 & $-0,28$ & 0,68 & $-0,42$ & $-141,599$ \\
\hline Bosques & 67,25 & $-3,4$ & 63,85 & $-1,93$ & 61,92 & $-1,17$ & 60,75 & $-9,38$ & 51,37 & $-15,88$ & $-5353,783$ \\
\hline Pastos & 24,45 & $-15,17$ & 9,28 & $-1,4$ & 7,88 & 7,82 & 15,7 & $-0,48$ & 15,22 & $-9,23$ & $-3111,802$ \\
\hline $\begin{array}{l}\text { Áreas } \\
\text { Urbanas }\end{array}$ & 4,02 & 3,17 & 7,19 & 2,8 & 9,99 & 3,05 & 13,04 & 4,47 & 17,51 & 13,49 & 4548,019 \\
\hline $\begin{array}{l}\text { Suelo } \\
\text { expuesto }\end{array}$ & 2,68 & 15,12 & 17,8 & 0,4 & 18,2 & $-11,15$ & 7,05 & 4,21 & 11,26 & 8,58 & 2892,661 \\
\hline $\begin{array}{l}\text { Áreas } \\
\text { agrícolas }\end{array}$ & 0,5 & 0,3 & 0,8 & 0,2 & 1 & 1,5 & 2,5 & 1,46 & 4 & 3,46 & 1166,504 \\
\hline
\end{tabular}

\section{Uso y ocupación de los suelos en el año 2003}

Todas las intervenciones antrópicas que ocurrieron en la región, como la construcción de la carretera Fernão Dias y del embalse Paiva Castro en la década de 1970, provocaron |significativos cambios económicos y ambientales en el municipio de Mairiporã. La construcción de esta carretera se destinaba a interconectar la gran São Paulo con Belo Horizonte y la construcción del embalse Paiva Castro tenía el objetivo de garantizar el suministro de agua potable a la Gran São Paulo. La cuenca hidrográfica del río Juqueri estaba siendo insertada en un área de intensos conflictos socioambientales en función de diversas características (Hoeffel et al., 2004).

entre estas características se puede destacar el hecho de que esta cuenca se integra con otra cuenca hidrográfica de gran importancia económica, pues esa es parte fundamental del Sistema Cantareira de abastecimiento de agua. El mismo autor todavía plantea que, aunque la región se venía consolidando como un importante polo turístico y con un intenso proceso de urbanización, la población local parece no percibir o no tener conocimiento de las peculiaridades ambientales de la región que impulsan en gran parte el turismo que se desarrolla actualmente (HOEFFEL et al., 2004).

Otra actividad que ganó mucha fuerza en la región fue a la silvicultura, que hoy ocupa extensas áreas en el Sistema Cantareira y continúa en expansión (Whately \& Cunha, 2007). Esta situación evidencia enormes riesgos existentes para la calidad del agua del embalse Paiva Castro, así como la necesidad de intensificar los procedimientos que pueden garantizar la conservación y la recuperación de sus recursos hídricos.

De acuerdo con los datos obtenidos, en el año 2003, nuevamente los cuerpos de agua perdieron el 0,07\% de su área en relación al año 
1992, el bosque perdió el 1,93\% y las áreas de pastoreo perdieron el 1,4\%, las clases de áreas urbanas y suelo expuesto aumentaron sus áreas en $2,8 \%$ y el 0,4\% respectivamente (Tabla 3). Por lo tanto, en el año 2003 se determinó un paisaje formado por mosaicos, donde apenas se distingue una continuidad de apariencia entre una propiedad rural y otra, lo que revela intervención humana y la discontinuidad de los ecosistemas (Almeida et al., 2008) (Figura 4).

\section{Uso y ocupación de los suelos del año 2011}

Según el Plan Director del municipio de Mairiporã, la cobertura natural antiguamente estaba dominada por formaciones forestales, que hoy en día vienen siendo reemplazadas gradualmente por núcleos urbanos, reforestaciones y agroecosistemas. Se identificó un aumento en el área de pastoreo para este año, que pasó del 7,88\% en el año 2003 a un 15,7\% para el año 2011. Este fenómeno podría haber ocurrido por el crecimiento de pastoreo de algunas áreas de suelo expuesto, ya que la clase disminuyó del 18,2\% del año 2003 a un valor del 7,05\% en el año 2011, protegiendo los suelos susceptibles a la erosión (Figura 4).

Muchos de los valores obtenidos en esta investigación en los mapas de uso del suelo de la cuenca, fueron confrontados, evaluados y validados según los resultados obtenidos en el documento "Atlas de Uso y Ocupación del suelo del Municipio de Mairiporã" de 2006, que mostró resultados similares a los mapas de suelo en áreas urbanas. Para el año 2011, la dinámica en el uso de los suelos de la Cuenca del río Juqueri mostró nuevamente aumentos en las clases de uso antrópico. La clase de áreas urbanas evidenció un incremento del 3,05\% y la clase de área agrícola $1,5 \%$, mostrando degradación continua de la cuenca en el transcurso del tiempo. La clase de cuerpos de agua disminuyó 0,05\%, y la de bosque 1,17\%, evidenciando la degradación en los recursos hídricos, y la clase de suelo expuesto disminuyó en el $11,15 \%$, lo que sugiere que ese porcentaje se distribuyó en el incremento de áreas de pastoreo que aumentó en el 7,82\% y en el área urbana (Tabla 3).

\section{Uso y ocupación de los suelos en el año 2016}

La situación de la Cuenca del río Juqueri y de sus recursos hídricos para el año 2016 es el resultado de largos procesos de cambios en el uso del suelo. En cierta forma, la distribución de la red de drenaje, los diferentes procesos erosivos, la formación del embalse Paiva Castro y su dinámica con los acuíferos subterráneos, además de la distribución de la vegetación y otros elementos físicos que interfieren en la organización y ocupación del área urbana y pastos se relacionan con el uso del suelo de la cuenca. Siendo de gran importancia entender las interacciones de los usos y la estructuración paisajística, para determinar la degradación de los recursos hídricos y la presión ambiental actual. Por lo tanto, la cuenca está pasando por procesos degradantes de ocupación antrópica en los últimos 30 años, lo que está causando graves reflejos ambientales, como la disminución del bosque y la degradación de los recursos hídricos en cantidad y calidad. El embalse Paiva Castro sufre una continua degradación, pues su área disminuye paulatinamente de acuerdo con los datos obtenidos por esta investigación, el embalse cuenta ahora con menos del 0,28\% (Tabla 3).

\section{Degradación de los recursos hídricos de la cuenca del río Juqueri}

Los mapas evidencian resultados del progresivo aumento de áreas urbanas y disminuciones de áreas forestales y las áreas ocupadas por los recursos hídricos disminuyeron, lo que de hecho demuestra una degradación de los recursos hídricos en el transcurso de los años. Los valores en el área de la clase cuerpos de agua disminuyeron 
142 ha desde 1986 hasta 2016, o sea, se ha perdido un área del 0,42\%. La clase de bosque disminuyó 5354 ha en los mismos 30 años, lo que en porcentaje representa una pérdida del $15,88 \%$, valor relevante para este estudio (Tabla 3) (Figura 4). El área cubierta por pasturas disminuyó 3111 ha, lo que en porcentaje sería el 9,23\%. Lo contrario ocurrió para el área urbana y el suelo expuesto, que aumentaron su área en 4548 ha y 2893 ha respectivamente, lo que en porcentaje representa un aumento del $13,49 \%$ y del $2,9 \%$.

Por más que el valor de la disminución del área de los cuerpos de agua sea sólo el 0,42\%, el uso de suelos tiene una relación directa con el flujo de agua del área del Parque Estadual Juqueri y de la cuenca Juqueri, siendo que esta cuenca es drenada por el río Juqueri que además de su disminución, recibe aguas residuales de la zona metropolitana de São Paulo (RMSP), donde además el Embalse recibe aguas residuales del sistema Cantareira, compuesto por las cuencas Atibainha, Cachoeira, Jacar, Jáguari y Juqueri, responsable del $56,70 \%$ del abastecimiento de agua de la Región Metropolitana de São Paulo (RMSP). El uso del área de la Cuenca del río Juqueri en la represa se rige por la Ley de Protección de los Manantiales - Ley Estadual n ${ }^{\circ}$ 9.866, de 28/11/1997. Pero, aun así, se está redujendo su área boscosa (Figura 5 ). Se resalta que, así como viene ocurriendo una disminución de las áreas de los cuerpos de agua, aumentando asi la bioacumulación y biodisponibilidad de determinados contaminantes en los sedimentos del embalse Paiva Castro (Figura 6). Lo que ocasiona impactos sobre la salud de las personas usuarias del abastecimiento por este embalse, pues el nivel actual de ese es del 19,9\% del nivel total del reservatorio (Sedae, 2017).

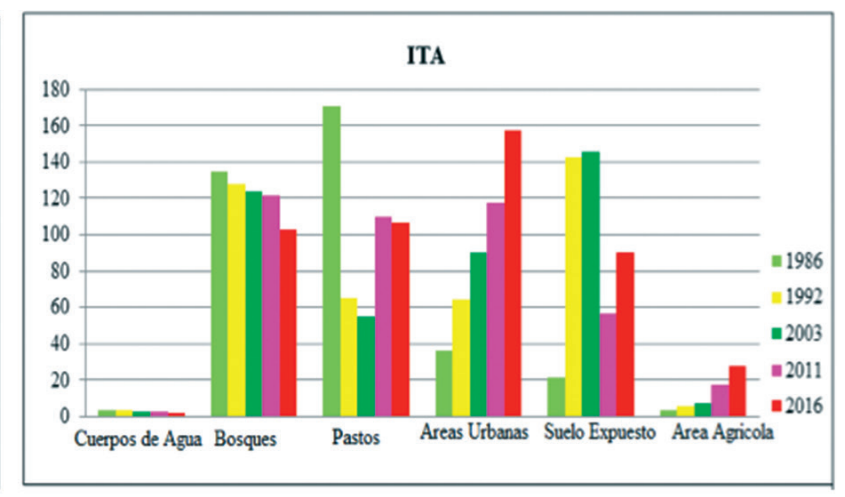

Figura 4. Cambios en el uso del suelo de la cuenca y ITA

Fuente: Elaboración propia.

Cuerpos de agua

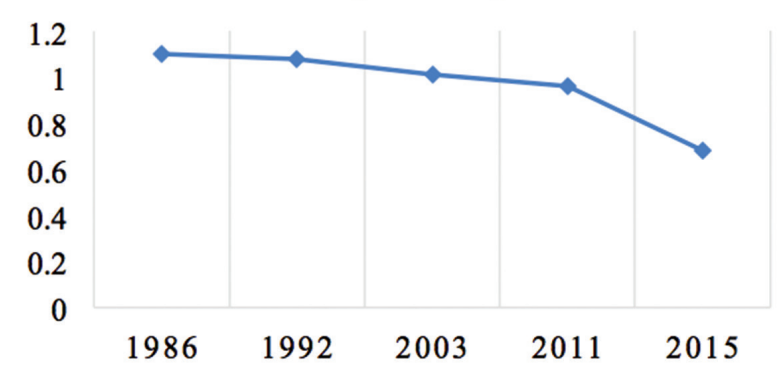

Figura 5. Disminución en \% del área de la clase cuerpos de agua Fuente: Elaboración propia. 


\section{Aplicación del índice de transformación antrópica (ITA)}

La Tabla 4 muestra los resultados del ITA, que varió de 3,7, en el año 1986 y fue para 4,87, en el año 2016, evidenciando que ocurrió la degradación $76 \%$ a partir del año 1986. La Figura 5 identifica la dinámica sufrida por la cuenca en los años estudiados $y$, nuevamente, queda muy nítida la disminución de la clase bosque. Se observó también un aumento en la clase de pastoreo. También hubo variabilidad en la clase de suelo expuesto, que habiendo sufrido inicialmente una disminución, aumentó en el año 2016 superando, inclusive, los valores presentados en 1986 y 2011. Por lo cual, existe una leve disminución consecutiva de los valores de la clase en los cuerpos de agua a través de los años.

Se identifica la presión ambiental en los cambios del uso del suelo, pues los mayores impactos se registraron en el período de los años 2011 hasta 2016, periodo en el cual se obtuvieron los mayores valores de pérdidas en áreas de clases muy importantes como los cuerpos de agua y los bosques (Figuras
5 y 6). En particular, las disminuciones ocurrieron en las clases de bosque, pastos y cuerpos de agua, proceso acompañado de aumentos en los valores del ITA de áreas degradantes como la clase de suelo expuesto que pasó del año 2011 de un valor de 56,4 a 90,08 en 2016 y cuando el área urbana pasó de un valor de 117,36 en el año 2011 a un valor de 157,59 en los años 2016. Se evidencia una clara y progresiva degradación ambiental de la cuenca (Tabla 4). Cabe resaltar que el ITA identificó la clase de pastos como el área más importante con un valor de 171,15 en el año 1986 , siendo esta clase muy relevante en la planificación a futuro de la cuenca para su gestión y mejoramiento ambiental (Figura 5).

Por lo tanto, se clasificó, según el ITA, la Cuenca del río Juqueri como una cuenca Regularmente Degradada, manteniéndose en ese nivel de degradación regular en los últimos 30 años. Sin embargo, los valores de ITA vienen aumentando, lo que demuestra una intensificación en la presión y degradación ambiental que la cuenca y en sus recursos hídricos.

Tabla 4. Valores del ITA.

\begin{tabular}{l|c|c|c|c|c}
\hline Clases & $\mathbf{1 9 8 6}$ & $\mathbf{1 9 9 2}$ & $\mathbf{2 0 0 3}$ & $\mathbf{2 0 1 1}$ & $\mathbf{2 0 1 6}$ \\
\hline Cuerpos de Agua & 3,3 & 3,24 & 3,03 & 2,88 & 12,04 \\
\hline Bosques & 134,5 & 127,7 & 123,84 & 121,5 & 102,74 \\
\hline Pastos & 171,15 & 64,96 & 55,16 & 109,9 & 106,54 \\
\hline Áreas Urbanas & 36,18 & 64,71 & 89,91 & 56,4 & 90,08 \\
\hline Suelo Expuesto & 21,44 & 142,4 & 145,6 & 17,5 & 27,72 \\
\hline Áreas Agrícolas & 3,5 & 5,6 & 7 & 426 & 487 \\
\hline Total & 370 & 409 & 425 & Regular \\
\hline Clasificación ITA & Regular & Regular & Regular & Regular \\
\hline
\end{tabular}




\section{Conclusiones}

El aumento poblacional trae consigo aumentos en el área urbana, acompañada de diversas interferencias antrópicas ligadas al mal uso del espacio urbano, que en conjunto hacen que la Cuenca del río Juqueri esté sometida a una fuerte presión ambiental, se concluye que la Cuenca del río Juqueri pasó por un proceso degradante de ocupación antrópica en los últimos 30 años, lo que está causando graves problemas ambientales, como la disminución del área boscosa que conlleva a pérdidas de fauna y flora, y la disminución de los cuerpos de aguas.

El embalse Paiva Castro es una de las mayores riquezas de esta cuenca, este viene sufriendo fuertes impactos debido al aumento del área urbana en su perímetro (construcciones de edificios y condominios), estos procesos sin la debida planificación, viene acompañado de aguas residuales que se vierten sin previo tratamiento degradando sus recursos hídricos.

Esta investigación muestra progresivas disminuciones en las áreas de la cuenca del rio Juqueri, cubiertas con capas forestales, pastizales y áreas ocupadas por los recursos hídricos, esto demuestran una presión ambiental en el transcurso de los años, donde el crecimiento del área urbana intervino en la dinámica del paisaje de la cuenca, y trajo como consecuencia la disminución de los cuerpos hídricos de la cuenca del rio Juqueri y del embalse Paiva Castro.

Se determina según el ITA obtenido para la cuenca del río Juqueri que es una cuenca Regularmente Degradada, manteniendo este nivel de degradación regular en los últimos 30 años, sin embargo, los valores de ITA vienen aumentando, mostrando una fuerte intensificación de la presión ambiental en la cuenca y una continua degradación en sus recursos hídricos.

\section{Literatura citada}

ALMEIDA CE, ALMEIDA JR, COSTA J. SILVEIRA AC, VINHAES MC, 2000. Monitoring the domiciliary and peridomiciliary invasion process of Triatoma rubrovaria in the state of Rio Grande do Sul, Brazil. Mem Inst Oswaldo Cruz 95: 761-768.

ALMEIDA CE, COSTA J. DOTSON E, HAAG K, DUPAS $S$, PACHECO RS, 2008. Inferring from the cyt $B$ gene the Triatoma brasiliensis Neiva, 1911 (Hemiptera: Reduviidae: Triatominae). Genetic structure and domiciliary infestation in the state of Paraíba, Brazil. Am J Trop Med Hyg 78: 791-802.

ALMEIDA CE, BELTRÃO $M$, COSTA J. DUARTE R, FOLLY-RAMOS E, GUMIEL M, LIMA MM, LIMANEIVA V, LOCKS M, PETERSON AT, 2009. Could Triatoma sherlocki be vectoring Chagas disease in small mining communities in Bahia, Brazi. Med Vet Entomol, in press.

ATLAS DE USO E OCUPAÇÃO DO SOLO DE MAIRIPORÃ 2006. https://www.emplasa.sp.gov.br/ Cms_Data/Sites/EmplasaDev/Files/Documentos/Cartografia/Atlas/RMSP/Atlas_Mairipora.pdf. Acesso: 10/10/2016.

CUNHA, P., WHATELY, M. Cantareira 2006: um olhar sobre o maior manancial de água da Região Metropolitana de São Paulo. Instituto Socioambiental, São Paulo, 2007.

FADINI, A. A. B. Impactos do Uso das Terras na Bacia Hidrográfica do Rio Jundiaí (SP). Rio Claro: Universidade Estadual Paulista (UNESP), Dissertação de Mestrado em Geociências e Meio Ambiente, 141 p., 2003.

FADINI, A. A. B. Sustentabilidade e identidade local: pauta para um planejamento ambiental participativo em sub-bacias hidrográficas da região Bragantina. Rio Claro: Universidade Estadual Paulista, Instituto de Geociências e Ciências Exatas. Tese de Doutorado, 204p., 2005.

GIATTI, L. Reservatório Paiva Castro - Mairiporã - SP Avaliação da Qualidade da Água Sobre Alguns Parâmetros Físicos, Químicos e Biológicos. Dissertação de Mestrado. Universidade de São Paulo. 2000.

HADDAD, E. Influências antrópica na qualidade da água da bacia hidrográfica do rio São Miguel, Carste do alto São Francisco, Minas Gerais. 2007. 156 f. Dissertação (Mestrado em Geografia) - Programa de pós-graduação em geografia, Universidade Federal de Minas Gerais - UFMG, Belo Horizonte, 2007. 
HOEFFEL et al., Concepções Sobre a Natureza e Sustentabilidade. Um Estudo sobre Percepção Ambiental na Bacia Hidrográfica do Rio Atibainha-Nazaré Paulista/SP. II Encontro da ANPPAS. Indaiatuba, Brasil: ANPPAS (CD-ROM), 2004. ALMEIDA JR et al,, 2008)

LÉMECHEV. T. (1987). On hydrological heterogeneity catchment morphology and catchment response. Journal of Hydrology, 100, p 353-375.

LEITE M, MATSUMOTO T., AVALIAÇÃO DA QUALIDADE DA ÁGUA DO RESERVATÓRIO DE ILHA SOLTEIRA (BRASIL) VISANDO SEU APROVEITAMENTO MÚLTIPLO. Departamento de Engenharia Civil - Faculdade de Engenharia de Ilha Solteira - Universidade Estadual Paulista - Processo 03/07355-2007

MANTOVANI, W. 2003. Delimitação do bioma Mata Atlântica: implicações legais e conservacionistas. Ecossistemas Brasileiros: Manejo e Conservação. $1^{\circ}$ ed. Expressão Gráfica e Editora, Fortaleza, p.287-295.
MATEO, J. Apuntes de Geografía de Los Paisajes. La Habana: Universitaria, 1984. 194p.

PÉREZ-ORTEGA, D. J. Avaliação dos efeitos das atividades antrópicas na bacia hidrográfica do Córrego do Ipê, município de Ilha Solteira-SP. 2011. 151 f. Dissertação (Mestrado em Engenharia Civil) - Universidade Estadual Paulista "Júlio de Mesquita Filho", São Paulo, 2011.

SANTOS, DIAS. SILVA, MACEDO. ANÁLISE HIDROLÓGICA E SOCIOAMBIENTAL DA BACIA HIDROGRÁFICA DO CÓRREGO ROMÃO DOS REIS, VIÇOSA-MG. Revista Sociedade de Investigações Florestais. 2009. v.31, n.5, p.931-940

SEDAE. Fundação Sistema Estadual de Análise de Dados. Perfil Municipal. 2008. Disponível em: <http://www.seade.gov.br/produtos/perfil/perfil. php>. Acesso em: 04/10/2016.

USGS. http://earthexplorer.usgs.gov/ Acesso: 20/11/2016 